\title{
Current helmet and protective equipment usage among previously injured ATV and motorcycle riders
}

\author{
R S Mangus, C J Simons, L E Jacobson, E W Streib, G A Gomez
}

Injury Prevention 2004;10:56-58. doi: 10.1136/ip.2003.002626

See end of article for authors' affiliations .....................

Correspondence to: Dr R S Mangus, Emerson Hall, Department of Surgery, 545 Barnhill Drive, Indianapolis, Indiana 46202, USA; rmangus@iupui.edu
Injury recidivism among trauma patients may be related to an individual pattern of high risk behaviors. The extent to which an injury episode modifies this behavior pattern is unknown. A self report, voluntary, anonymous, cross sectional survey was administered to motorcycle and all-terrain vehicle (ATV) riders at a popular recreation site. Data included demographics, injury history, and current usage of helmet and protective gear. Two hundred eighty surveys were completed. History of ATV/motorcycle related minor and major injury were reported by $21 \%$ and $9 \%$, respectively. Persons with a history of minor ATV/ motorcycle injury only were less likely to use a helmet or protective equipment $(78 \% \vee 74 \%, p=0.58$ and $49 \%$ v $41 \%, p=0.29)$. Persons with a history of any major ATV/motorcycle injury were also less likely to use a helmet or protective equipment $(77 \% v 56 \%, p=0.03$ and $48 \% v 40 \%, p=0.53)$. These findings suggest a pattern of persistent high risk behavior among previously injured persons. l: jury recidivism among trauma patients is well documented and may result from an accumulation of risk factors such as male gender, adolescent and young adult age groups, heavy alcohol or drug use, abuse, poverty, and geographic origin. ${ }^{1-6}$ Additionally, these persons may be less likely to adopt proactive behaviors such as use of seatbelts and helmets, use of a designated driver, obeying traffic laws, and avoidance of volatile psychosocial situations. ${ }^{7}$ The extent to which an individual injury episode modifies this pattern of high risk behaviors is unknown.

An identified population at increased risk for injury is riders of motorcycles and all-terrain vehicles (ATVs). ${ }^{8-10}$ Many countries and all states in the United States have laws governing the use of these vehicles. Nevertheless, protection from injury requires the individual rider to electively use a helmet and protective equipment on a routine basis. This study compares the use of helmets and protective equipment by motorcycle and ATV riders with and without a history of previous ATV/motorcycle related injury.

\section{METHODS}

A self report, anonymous survey was distributed over a four week period to ATV and motorcycle users at a popular recreation site. The survey gathered data regarding demographics, motorcycle and ATV usage, and injury history. The survey required approximately 10 minutes for completion, and surveys were sealed in an unmarked envelope by each subject. Participants were offered a candy bar or soda as an incentive. Children younger than age 15 were required to complete the form with parental assistance. Data entry and analysis were completed at a separate time and location. Questions included in the survey were adopted from the Behavioral Risk Factor Surveillance System, but the questionnaire itself was not independently validated.

Minor ATV/motorcycle related injuries were defined as any traumatic injury requiring evaluation by a health care provider in a professional setting but not requiring hospitalization. Major injuries included those requiring at least overnight hospitalization. Further injury details were not collected and injury reports were not verified. Usage of helmets and protective equipment was evaluated using a five point scale ranging from "never" to "always". Protective equipment was defined as protective clothing and included pads, masks/goggles, gloves, and hearing protection. For analysis, persons reporting either "always" or "almost always" using helmets and/or protective equipment were recorded as "users" of these devices. Data were analyzed with standard statistical software using the $\chi^{2}$ test (SPSS for Windows, version 11.5, 2002).

\section{RESULTS}

Two hundred eighty surveys were completed. One hundred eleven $(40 \%)$ of respondents were ages 16-21, with $16 \%$ being 15 years of age or younger (age range 4-61). Seventy percent of the subjects were males, $52 \%$ were from rural areas or small towns, and 9\% (of adults) had less than a high school education with $25 \%$ being college graduates (see table 1).

A lifetime history of minor ATV/motorcycle injury only was reported by $21 \%$ of respondents and major injuries by $9 \%$. The rate of injury was greatest in the 16-21 age group and among males and those from rural areas. Current helmet use was reported by $75 \%$ overall, and the use of protective equipment by $47 \%$. Use of a helmet was lower for persons of a younger age, rural background, and with less education. These trends were similar for use of protective equipment (see table 2).

Persons with a history of a minor ATV/motorcycle injury only were less likely to use a helmet or to use protective equipment ( $78 \% \vee 74 \%, \mathrm{p}=0.58$ and $49 \% \vee 41 \%, \mathrm{p}=0.29)$. Persons with a history of major injury were also less likely to use a helmet or protective equipment $(77 \% \vee 56 \%, p=0.03$ and $48 \% v 40 \%, p=0.53)$. Persons with a history of either minor or major injury were also less likely to use a helmet and protective equipment $(78 \% v 68 \%, \mathrm{p}=0.09$ and $49 \% v$ $47 \%, \mathrm{p}=0.23$ ) (see table 3 ).

\section{DISCUSSION}

Persons with a history of both minor and major ATV/ motorcycle related injury were less likely to report current use of either helmets or protective equipment compared to persons without a previous injury. Subjects with a history of major ATV/motorcycle injury have the greatest impetus for behavioral changes and would be expected to have the highest rate of protective equipment usage. Yet, subjects in this study with a history of major injury were the group least likely to report both current helmet and protective equipment 
Table 1 Comparison of the demographics of subjects with and without a history of any ATV/motorcycle injury; values are number $(\%)$

\begin{tabular}{|c|c|c|c|c|c|c|c|}
\hline & All & $\begin{array}{l}\text { History of minor } \\
\text { injury only }\end{array}$ & p Value & $\begin{array}{l}\text { Any history of } \\
\text { major injury }\end{array}$ & p Value & $\begin{array}{l}\text { History of } \\
\text { any injury }\end{array}$ & p-value \\
\hline Overall & $280(100)$ & $54(21)$ & & $25(9)$ & & 79 (28) & \\
\hline Gender & & & $<0.01$ & & 0.02 & & $<0.001$ \\
\hline Male & $195(70)$ & $47(27)$ & & $22(11)$ & & $69(35)$ & \\
\hline Female & $85(30)$ & $7(8)$ & & $3(3)$ & & $10(12)$ & \\
\hline Age group (years) & & & $<0.01$ & & 0.12 & & $<0.001$ \\
\hline$\leqslant 15$ & $45(16)$ & $4(9)$ & & $1(2)$ & & $5(11)$ & \\
\hline $16-21$ & $111(40)$ & $33(34)$ & & 15 (14) & & $48(43)$ & \\
\hline $22-30$ & $55(20)$ & $9(18)$ & & $4(7)$ & & $13(24)$ & \\
\hline$\geqslant 31$ & $69(25)$ & $8(12)$ & & $5(7)$ & & $13(19)$ & \\
\hline Hometown & & & 0.15 & & 0.02 & & 0.08 \\
\hline Rural & $128(46)$ & $33(28)$ & & 9 (7) & & 42 (33) & \\
\hline Small town & $17(6)$ & $3(25)$ & & $5(29)$ & & 8 (47) & \\
\hline Medium sized town & 36 (13) & $5(16)$ & & $5(14)$ & & $10(28)$ & \\
\hline Small city & $67(24)$ & $8(13)$ & & $5(8)$ & & $13(19)$ & \\
\hline Large city & 32 (11) & $5(16)$ & & 1 (3) & & $6(19)$ & \\
\hline Education/parental education & & & 0.95 & & 0.92 & & 0.93 \\
\hline Less than high school & $26(9)$ & $4(17)$ & & $2(8)$ & & $6(23)$ & \\
\hline High school graduate & $88(31)$ & $17(22)$ & & $9(10)$ & & $26(30)$ & \\
\hline Some college & 97 (35) & $19(22)$ & & $9(9)$ & & $28(29)$ & \\
\hline College graduate & $69(25)$ & $14(22)$ & & 5 (7) & & $19(28)$ & \\
\hline
\end{tabular}

usage. Though only one of the individual results reaches statistical significance, it is important to note that in each individual subgroup analysis, persons with a history of injury were less likely to use helmets or protective equipment. The largest absolute difference in usage rates was for helmet use among persons with a history of major injury. The helmet is the single most important protective device for avoidance of severe injury for riders of ATVs and motorcycles, and is the most widely publicized and legislated. It is important, then, that only one half of persons with a previous major ATV/ motorcycle injury were currently using a helmet.

These findings certainly suggest a pattern of persistent high risk behavior among previously injured persons, even when those injuries are severe. Whether this pattern of behavior is modified in comparison to pre-injury behavior cannot be ascertained from these data. However, these findings do suggest that persons with a history of injury remain at higher risk for recurrent traumatic injury than those persons not previously injured.
These findings support the previously described theory in which risk taking is a constellation of behaviors. ${ }^{711}{ }^{12}$ Injury recidivism likely results from a combination of continued high risk behaviors and a failure to adopt proactive, protective behaviors. This study demonstrates that previously injured persons engaging in a high risk activity do not utilize readily available protective equipment at the same rate as non-injured persons. Therefore, behavior modification interventions in the trauma population must focus not only on avoidance of negative behaviors but also on reinforcing the adoption of protective behaviors. As previously demonstrated, the target group for intervention should be adolescent and young adult males from rural areas or small towns. This study also supports the assertion that the greatest risk factor for traumatic injury is the history of a previous traumatic injury, as the injury episode does not appear to have a significant impact on modifying high risk behaviors. Future research of this type should focus on identifying the motivation for use and non-use of protective equipment. This

Table 2 Use of protective equipment stratified by demographic variables; values are number (\% of group using)

\begin{tabular}{|c|c|c|c|c|}
\hline & $\begin{array}{l}\text { "Always" or "almost } \\
\text { always" use helmet }\end{array}$ & p Value & $\begin{array}{l}\text { "Always" or "almost always" } \\
\text { use protective clothing }\end{array}$ & p Value \\
\hline Overall & $211(75)$ & & $131(47)$ & \\
\hline Gender & & 0.13 & & 0.36 \\
\hline $\begin{array}{l}\text { Male } \\
\text { Female }\end{array}$ & $\begin{array}{l}152(78) \\
59(69)\end{array}$ & & $\begin{array}{l}95(49) \\
36(42)\end{array}$ & \\
\hline Age group (years) & $54(69)$ & 002 & $36(42)$ & $<0.001$ \\
\hline$\leqslant 15$ & $32(71)$ & & $25(56)$ & \\
\hline $16-21$ & $75(68)$ & & $29(26)$ & \\
\hline $22-30$ & $44(80)$ & & $33(60)$ & \\
\hline$\geqslant 31$ & $60(87)$ & & $44(64)$ & \\
\hline Hometown & & $<0.001$ & & $<0.001$ \\
\hline Rural & $84(66)$ & & $39(30)$ & \\
\hline Small town & $12(71)$ & & $5(29)$ & \\
\hline Medium sized town & $23(64)$ & & $16(44)$ & \\
\hline Small city & $62(92)$ & & $46(69)$ & \\
\hline Large city & $30(94)$ & & $25(78)$ & \\
\hline Education/parental education & & $<0.01$ & & $<0.001$ \\
\hline Less than high school & $13(50)$ & & $2(8)$ & \\
\hline High school graduate & $63(72)$ & & $36(41)$ & \\
\hline Some college & $79(81)$ & & $51(53)$ & \\
\hline College graduate & $56(81)$ & & $42(61)$ & \\
\hline
\end{tabular}


Table 3 Use of protective equipment stratified by history of ATV/motorcycle related injury; values are number $(\%)$

\begin{tabular}{|c|c|c|c|c|}
\hline & $\begin{array}{l}\text { "Always" or "almost } \\
\text { always" use helmet }\end{array}$ & p Value & $\begin{array}{l}\text { "Always" or "almost always" } \\
\text { use protective clothing }\end{array}$ & "p Value \\
\hline No history of minor injury (only) & $157(78)$ & 0.58 & $99(49)$ & 0.29 \\
\hline History of minor injury (only) & $40(74)$ & & $22(41)$ & \\
\hline No history of major injury & $197(77)$ & 0.03 & $121(48)$ & 0.53 \\
\hline History of major injury & $14(56)$ & & $10(40)$ & \\
\hline No history of any injury & $157(78)$ & 0.09 & $99(49)$ & 0.23 \\
\hline History of any injury & $54(68)$ & & $131(47)$ & \\
\hline
\end{tabular}

on-site, questionnaire-type study was effective in that there was a high rate of participation and it benefited from a large percentage of the participants having experienced previous traumatic injury.

\section{ACKNOWLEDGEMENT}

This paper was presented at the meetings of the Indiana Chapter of the American College of Surgeons, Indianapolis, 2002.

\section{Authors' affiliations}

R S Mangus, Department of Surgery, Indiana University School of Medicine

C J Simons, L E Jacobson, E W Streib, G A Gomez, Department of Surgery, Indiana University School of Medicine and Wishard Health Services, Indianapolis, Indiana

\section{REFERENCES}

1 Field CA, Claassen CA, O'Keefe G. Association of alcohol use and other highrisk behaviors among trauma patients. J Trauma 2001;50:13-19.
2 Cherpitel CJ. Substance use, injury, and risk-taking dispositions in the general population. Alcohol Clin Exp Res 1999;23:121-6.

3 Kaufman CR, Branas CC, Brawley ML. A population-based study of trauma recidivism. J Trauma 1998;45:325-32.

4 Hedges BE, Dimsdale JE, Hoyt DB, et al. Characteristics of repeat trauma patients, San Diego County. Am J Public Health 1995:85:1008-10.

5 Williams JM, Furbee PM, Hungerford DW, et al. Injury recidivism in a rural ED. Ann Emerg Med 1997;30:176-80.

6 Redeker NS, Smeltzer SC, Kirkpatrick J, et al. Risk factors of adolescent and young adult trauma victims. Am J Crit Care 1995:4:370-8.

7 Spain DA, Boaz PW, Davidson DJ, et al. Risk-taking behaviors among adolescent trauma patients. J Trauma 1997;43:423-6.

8 Cvijanovich NZ, Cook U, Mann NC, et al. A population-based assessment of pediatric all-terrain vehicle injuries. Pediatrics 2001;108:631-5.

9 Lynch JM, Gardner MJ, Worsey J. The continuing problem of all-terrain vehicle injuries in children. J Pediatr Surg 1998;33:329-32.

10 Rowland J, Rivara F, Salzberg, et al. Motorcycle helmet use and injury outcome and hospitalization costs from crashes in Washington state. Am J Public Health 1996;86:41-5.

11 Spaite DW, Criss EA, Weist DJ, et al. A prospective investigation of the impact of alcohol consumption on helmet use, injury severity, medical resource utilization, and health care costs in bicycle-related trauma. J Trauma 1995;38:287.

12 Zuckerman $M$. The psychophysiology of sensation seeking. J Pers 1990;58:313. 